\title{
ICRL 13.746
}

March $30 ; 1977$

\section{Fina1 Report}

Covering the Perlod 11 January 1976 to 11 March 1977

s.......

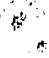

RESEARCH STUDIES ON SHORT OPIIGAL PULSE GENERATION FOR THE LASER FUSION PROGRAM

by

Dirk J.Kuizenga

SRI.Project 4908

Report HAP 77-21

Contract No.: $\$(04-3)-115$, Project Agreemeni No. 104

\section{Sponsored by:}

Lawrence L tvermore taboratories Universilty of Califormia Liyermore, California 94550 Attention Dr, Howard Lowdermilk Po. -1547503 


\section{INTRODUCTION}

In recent years, the stability and teliability. requirements of an oscillator for laser fuston systems such as Argus and Shlva have gone beyond what can reasonably be expected from a passively mode-locked Nd:YAG laser. It was alsc tealiźed that the most prom ing approach to satisfy the short pulse requirements of these systems was an actively mode-locked oscilliator.

one approach to develop a suitable oscillator was started at Stanford University in 1974 ( through 1976 (LLL subcontract 5247805). Fron earlier work t Stanford University, we kniew that a CW mode-locked Nd: ${ }^{2}$ AG laser cou 1 provide the necessary range of short pulses requtred for laser fuotion, $i$ i pulse? energles were too low. Some further work with a simultaneously mode-locked and Q-switched Nd:YAG laser ${ }^{3}$ showed that considerably more energy was

$\therefore$ available with this approach, and that undex certain operating conditions, short, transform-1imited puises could be obtafned. During the development programat Stanford University and SRI we fuliy investigated this approach.

In September 1976 we completed a prototypo 1aser, and measurements at SRI and LLL showed that the oscillator was very stable and reliable. Hence, it was decided to butld this type of oscillator for Shiva and also to assemble one of these osclilators at SRI for Argus. Thio laser was instalted on Argus in January 1977 , and was producing successful target s' ts at the writing of this report. 


\section{TECHICAL PROGRSS}

\section{Techilcal Considerations}

Active mode-lockl ng of the Nd YAG laser has been fnvestigated in detal1, and under steadystate conditions, the puige width is given by ${ }^{4}$

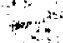

$$
\tau_{p}=\frac{(2 \ln 2)^{\frac{1}{2}} \mathrm{~B}^{2}}{\theta^{2}}\left(\frac{1}{f_{m} \cdot \Delta f}\right)^{\frac{1}{2}} \therefore
$$

where $f$ externd 1 modulation frequency

$$
\Delta \mathbf{f}=\text { linewidth }
$$

geround trip amplitude gain

$\theta=$ depth of modutation

The steady state puliei width Is determfied by two processes. On each rond trip in the cavity, when the pulse passes through the amplitude modulator, the pulse is phortened a b1t, and this contributes the factor $\left(\frac{1}{\theta_{n}}\right)$ tr equation (1). on each pass through the crystal, due to the linewidth of the active medium, the putse is lengthened a bit, and this contributes the factor $\mathrm{g}^{\frac{1}{4}} / \Delta \mathrm{f}^{2}$ to Equation (1). For typical operating conditions in a Ndy YG laser, the shortest pulses avallable are in the range of 50 to $100 \mathrm{ps}$ depending mainly on the modulation frequency, and Tence on the length of the cavity. For longer pulses, the effective bandwd th of the laser can be narrowed with an etclon, and the pul se widh ts then given by

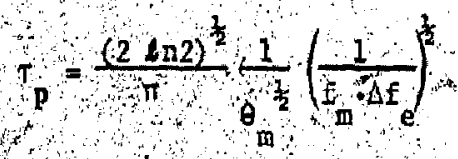


where $\Delta f$ is the effective bandwidth of the laser. In terms of the reflectivity $R$, thickness $h$, and index of refraction $n$ of the etalon, this bandwidth is given by

$$
\Delta \mathrm{f}_{\mathrm{e}}=\left(\frac{\mathrm{c}}{2 \pi \mathrm{nh}}\right) \frac{\mathrm{1}-\mathrm{R}}{\sqrt{\mathrm{R}}}
$$

For an uncoated etalon this becomes

$$
\Delta f_{e}=\left(\frac{2 c}{\pi h}\right) \frac{1}{n^{2}-1}
$$

The above equations completely predict the width of the pulses in a modelocked CW Nd:YAG laser, where we have steady.state conditions. In such a laser, the energy for single short pulses is in the range of 1 to $10 \mathrm{~nJ}$, and Is not sufficient for direct injection trito a typical Nd:Glass amplifier for laser fusion.

It is well known that a Nd:YAG laser can easily be Q-6wltched, and that peak power of $10^{4}$ times the typical $\mathrm{CW}$ power or more can be obtained. However, consideration of simul taneous mode-locking and Q-switching of $\therefore$ Nd:YAG laser shows that under almost all operating conditions of the laser, steady state tode-locking conditions are not acnieved, and the "resulting pulses are long, with a lot of nolsy substructure." Because build-up time of the Q-switched laser is always toc short for the modelijcking processs to reach steady state, some met. Jd must be devised to allow the mode-locking process to go to steady. state before the laser is Q-switched. Such a method is. shown in Figure 1.

The laser is pulsed in a quasi-CW way for several milliseconds, and the 10ss in the Q-switch Is adjusted so that the laser goes just above threshold. During this prelase period, the modulator is on all the time, and the mode-locking process can go to steady state. When the laser is $Q-$ sittched at the end of the quasi-ch period; the initial conditions in the cavity are transform-1imited, stable short pulses, and hence a stable Q-switched train of short pulses ls obtained. 

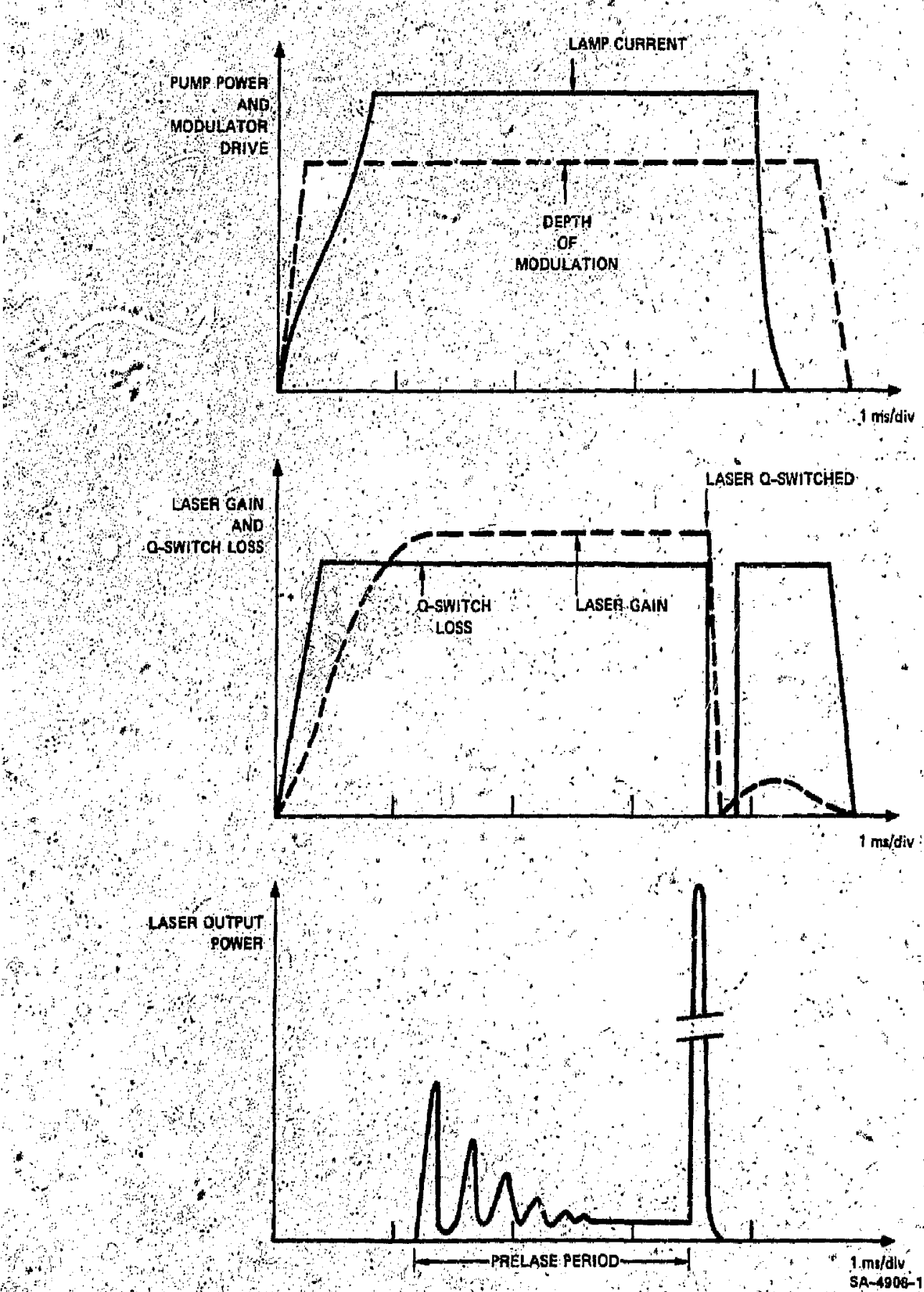

FIGURE 1:

Principle of operation of the mode-locked and Q-switched laser with prelave period, The long prelase period of several insecs allows the tode-locking process to reach steady state, and hence the initial. cond ltions when the lasef 1 s Q- ow tehed are stable, short, transformLtmil ted pulses 
To determine how long the prelase period must be to obtain transformlimited pulses, we must consider the transient build-up of the short puloes. When the laser goes above threshold, two processes start in the laser. First; the initial nolyy fleld in the cavity passes through the modulator and this staris to shape the envelope of the short pulses. On repeated passes through the modulator the pulse envelope gets shorter. Initialy, the linewidth has no effect on the pulse envelop. It is only when the pulse width approaches the steady state value that the linewidth takes effect and limits the pulse width to the steady state value given by Equation.(1): It can be shown that the pulse envelope is within $5 \%$ of steady state value after a number of round trips $M$ given by:

$$
M=\frac{0,38}{\sqrt{g} \theta_{m}}\left(\frac{\Delta f}{f}\right)
$$

Note the appearance of the ratio of the linewidth to the modulation frequency, $\Delta \mathrm{f} / \mathrm{f}$. Thls is typically on the order of $10^{3}$, and hence $1 \mathrm{t}$ takes that many round trips, or more, to reach steady state mode-locking conditions. This condition is easily satisfled during the prelese period,

The second process that starts when the laser goes above threshold is that the spectral width of the field tn the laser cavity narrows on each pass through the active medium (or etalon)، It is difficult to. precisely analyze this narrowing process in the presence of the modulator; but two approximate conditions can be obtainea. The bandwidth of the laser fleld is within a factor of two of that for a perfectly transformlimited pulse after a number of round trips given by:

$$
M>\frac{0.5}{\sqrt{g} \theta_{m}}\left(\frac{\Delta f}{f}\right)
$$

Tals is essentially the ame as the condition in Equation (5) above; accordingly, when the pulse envelope is within $5 \%$ of the steady state 
value, the opectral wldth of the pulbe is within a factor of two of the trang form $11 \mathrm{mit}$ of the steady state pulse.

A pore severe condition for obtalning good transform-limited pulses fo essentially the same as requiring single axial mode operation if the modulator is off - This conditton $1 \mathrm{~s}$ given by:

$$
{ }_{2}>\frac{\ln 2}{2 \mathrm{~g}}\left(\frac{\Delta \mathrm{f}}{\mathrm{fax}}\right)^{2}
$$

where $f$ is the axiat node spacing of the cavity for most operating conditions in a typica 1 yeyalaser, it takes a Eew miliseconds to satisty this copdition.

Qf, wally, the prelase perlod should also be long enough to let the relaxat1on oscillatrons dife away after the laser goes above threshold This usually take $a$ few upper level lifetimes of the active mediun; and hence the preiase period ghould be at least 0,5 to 1 ms for Nd YAG.

Experimenta1 1 , we find that a prelase perlod of 3 to 5 insec is convenient and satiffles a 11 to above conditions

A more tetalled andysis of this type of Nd YAG laser was given in an earifer report to LLL 4 In this report we calculated the single pulse energy that can be expected from this type of laser, and we discussed the factorsilnting, the pulse energy. It was show that single puise energles in the tange of 0.1 to 1 mJ can reasonably be expected from this type of lasex, with Nd, Yag, as the active tred um.

Work Accomplished

The major tasks of this research program were to develop the necessary hardware for a slmitaneous y mode-1ocked and Q-8Wftched Nd: YAG laser and to demonstrate the range of pulsew 1 ths avallable, as well as the single pulse energy range, and the amplttude and pulsewidh stablitty of these pujses one design philosophy that was adopted early in the program was 
to make ald the surfaces in the cavity at Brewster's angle. This had the following advantages:

$e^{-}$There wodld be no spurious etalon effects; whteh are probably responsible for most of the poor and anomalous behavior of mode-locked. Tasers.

Therel are no coat ngs inside the cav1ty, feducing the risk of optical damage to components.

o Insertion loss of all components is very low

- The lowest possible nolse level between pulses could be obta ned by reduclng backscatter and multiple reflection between components

A double ellipse pump cavity was developed for a Brewster angle crystal. To allow unj form cool-Ing, the chyatal and lamps had separate flow tubes, and the primp, cavity was flooded, It was decided to use an acousto-optic modulator and $Q-\$ 61$ tch. It is well known.that these modulators are acousticalyy resonant and can be very unstable under high RF drfve condtions due to heating of the substrate by heat generated in the transducer. This problem was solved by direct water cooling of the transducer. The nat advantage of using acousto-optic devices wis that fused quartz could be used as substrate material this gave good opticalquality substrate and low insertion loss and could easily be made at Brewster?s angle A typical arrangement of such a mode-locked and Q $\rightarrow$ itched laser is shown In Figure 2 .

Durling the prelase period, the laser is typically about $5 \%$ above threshold, and to obtain a stable prelase perlod it 18 thus extremely important that all the laser parameters are very stable during this pertod In particular, the signal to the Q owitch, the signal to to modulator, and the punp pow have to be stable, the latter requirement turned out to be a major problem, Initialiy, ow pumping was pianned for th1s osclilatior, but owlng to astigmatism lntroduced by the Brewster's ends of the rod thema focussing in the tod became a oevere problem 

Because of this astigmatism, the effective thermal focal length in the plane of the Brewster ends is shortce by no which makes CW, pumping of this laser imposible. However, since the maximum repetition rate of this laser has to be about 20 pulses per second, the thermal problem can be solved by pulsing the laser. The conventional L-C discharge type of pulsad pumping was rejected for this laser, because lt would be difficult to obtain the requirei constant pump power during the prelase period, and at best It could prolably only be obtained at one particular pump level. Since the required lamp currents are well withen the range of avallable power transistors, a transistor-regulated pulser was constructed several problens were encountered. It was found that the risetime of the highpressure krypton arc lamps used In these lasers was very slow, usually a few milliseconds, probably because of the slow arc expanston in the lamps, Instablitles of the famps and the avallable power supply also caused problems, and eventually a lamp artver was developed that had transistor-regulating circuits for proportional control of both the voltage and the lamp current A schematte diagram of this lamp controller is show in Figure $3(a)$, and. Figure $3(b)$ shows a multlple exposure of various lanp currents with this circult, the short- and long-term pump power fluctuations were less than $1 \%$

The flrst mode-locked and $Q$-switched laser that was assembled at sRI hat about a 4 , 5 -ns cavt ty round trip time, or a modulation frequency of

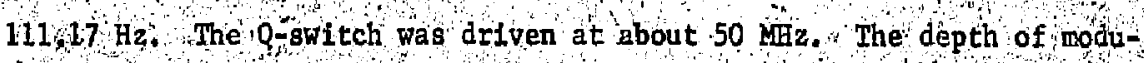
lation of the modulator was obtained by measurfing the single pass transmission of the modulator at $1.06 \mathrm{H}$ Assuming that the podulator operated In the Bragg diffraction reglon, we could ob tain the depthof nodulation,

$\theta^{2}$ he also measured the threshold punp power for a range of output couplers from of to $50 \%$, and from this te obtalned the laser gain as a function of the pump power from this, the also learned that the cavity round trip loss yas $2.7 \%$, not including the output coupling, indicating 

the very low insertion losses that can be achieved with all the components at Brewster's angle. The laser was usually operated at 20 pps, and we experienced no problems due to thermal focusstng. in the Nd;YG crystal

The pulse widths obtained from this lasec were measured with an optical correlator, using Type II SHG to measure the pulses. This type of correlator has been used before, ${ }^{3}$ but it has been considerably improved and automated for this work. A typical set of pulse width measurements are shown in Figure. 4 . These measurements were taken for $20-A$ lamp current: With no etalon, pulses from about 55 to 350 ps were obtained, and with a 1-cm uncoated quartz etalon, pulses, from about 250 ps to 1 ns were obtatned. This clearly shows that by simply adjusting the $R F$ drive to the modulator and using one, or perhaps a few etalons in the cavity, the pulse'width ican easily be adjusted over a wide range. The range of pulses that can be obtalned as a function of the RF drive for a particular setup $1 \mathrm{~s}$ well: defined.: With strong modulation, where the depth of modulation $\theta_{m}>1$, the output power from the laser decreases significantly, and the laser can easily go bel threshold for very strong modulation. For weak modulation.

$\therefore$ we find that at a certain level, the mode-1ocklng becomee unstable, a signiflcant noise leyel exists between the pulses, and the operation of the laser rapidly deteriorates. We find that these two 1imits are about the same with or yithout an etalon in the cavity. Between these limits, we always have stable and reliable mode-locking. The experizental results In Figure 4 were compared whth the theoretical predictions of Equatious (1) and (4). If we assume a linewidth of $175 \mathrm{GHz}$ for Nd:YAG, the theoret cal prediction agrees with the expecimental results: For the I-cm etalon, the predictions of Equations (2) and (4) agree well with the measured pulse widths.

Good performance of the laser was obtained with a $33 \%$ transmitcing output coupler at pump power levels were output coupling is approximately optimum for this case $(\sim 24-\mathrm{A}$ lamp surrent), we have about 10 short pulses within the $Q$-switched pulse envelop, allowing selection of a stable pulse 


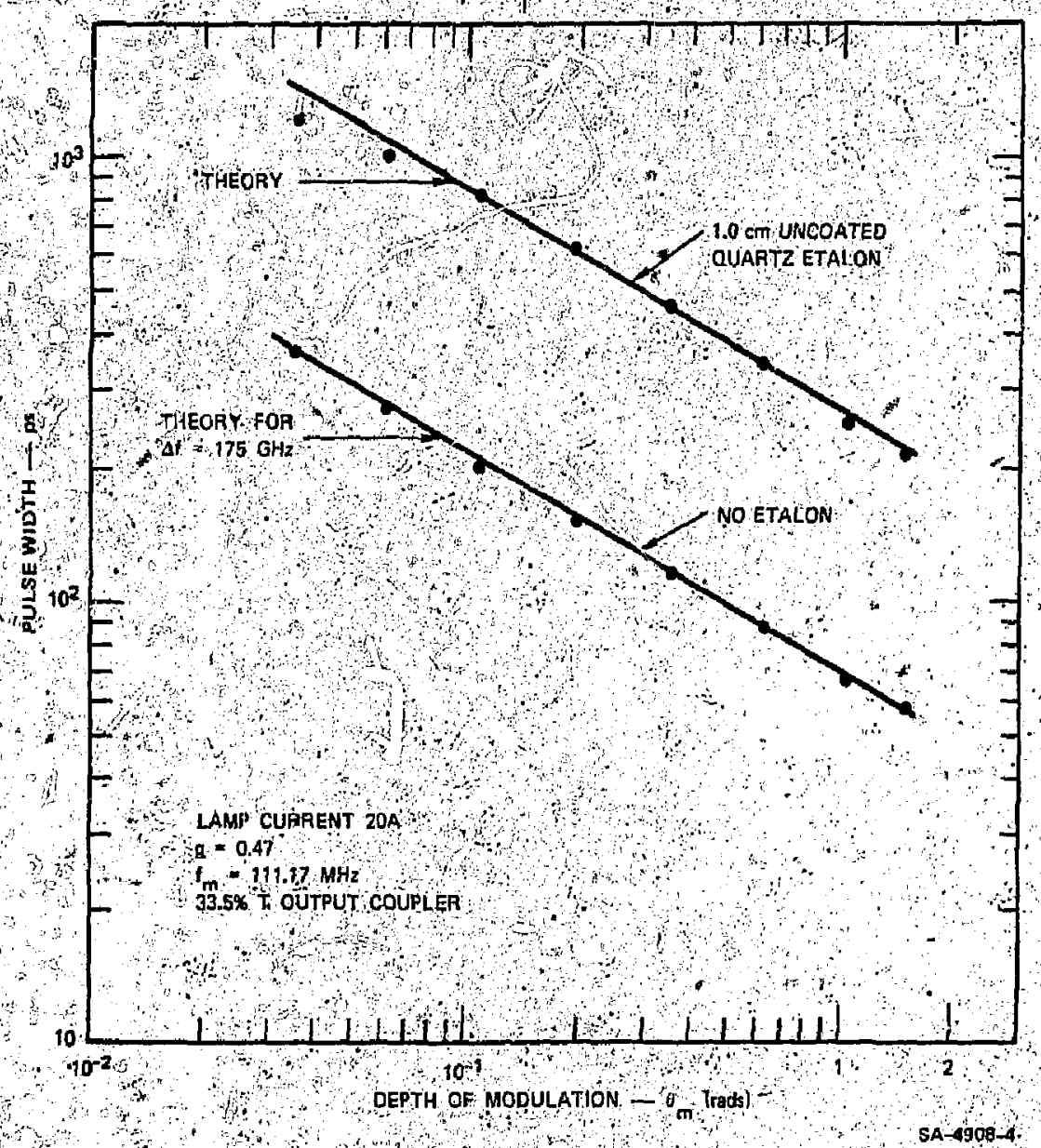

fIGURE 4

Range of short $t$ pulses available for lidyolaser for typical operating conditions. Pulses as short as $60 \mathrm{ps}$ can te obtained in this short laser cavity. The entire range of short pul beg can be obtained with only one uncoated quartz etalon. 
near the center of the pulise train. We measured the average power from the laser at 20 pps, and also recorded the pulse train with a fast detector. From this, we calculated the energy of a single pulse at the peak of the ful treln these regults are shown In figure 5 for varlous lamp currents. Wth tbls lases, purse energies up to 400 u were obtained We also noted a rapid decrease $n$ output energy for gtrong modulation, butt the reason for this is currently not well understood.

at this stage of the research effirt, the prototype laser was taken to Iivernore for further tests, where ye obtalned more, accurate statistical data on the stability of the laser. The output pulse train was recorded on a transfent digitizer, and the compter then measured the relative energy of a single pulse with the saxititim energy, Fitgure $6(\mathrm{a})$ abws a typical pulse train recording In each data run, we recorded 500 pulse trains. A typical histogram for 500 pulses is show in Figure $6(\mathrm{~b})$. the - width (FWM) of the histogram is less than $3 \%$ with no spurious putses cutslde the $\pm 3 \%$ tange We obtained this type of behavior for al1 pump levels well above threshold and for all depths of modulation where we have good mode-locking as described previously. It was malnly on the basis of these stability measurements that it was decided to use this type of osclilator for Shive He aloo did some streak camera measurements, and in general conflirmed the tange of pulse thd tho measured previously at SRI. More Important, we found that there was (as expected) no fine atructire on the pulses, nor were there any double pulses. The pulse shape was always smooth and sympeticical.

Durlng this research effort, we also found that the prelase method has some other advantages, puring the prelase perlod, the galn In the laser is equal to the $Q$-switch loss plus other losses, which is constant, and thus the galn is constant. Any fluctuation in pump power causes output power fluctuations, but the galn, and hence the stored energy, remains contant When the laser o $0-$ switched, the resulting $Q-8 w i t c h e d$ pulse 


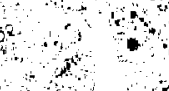

$x$
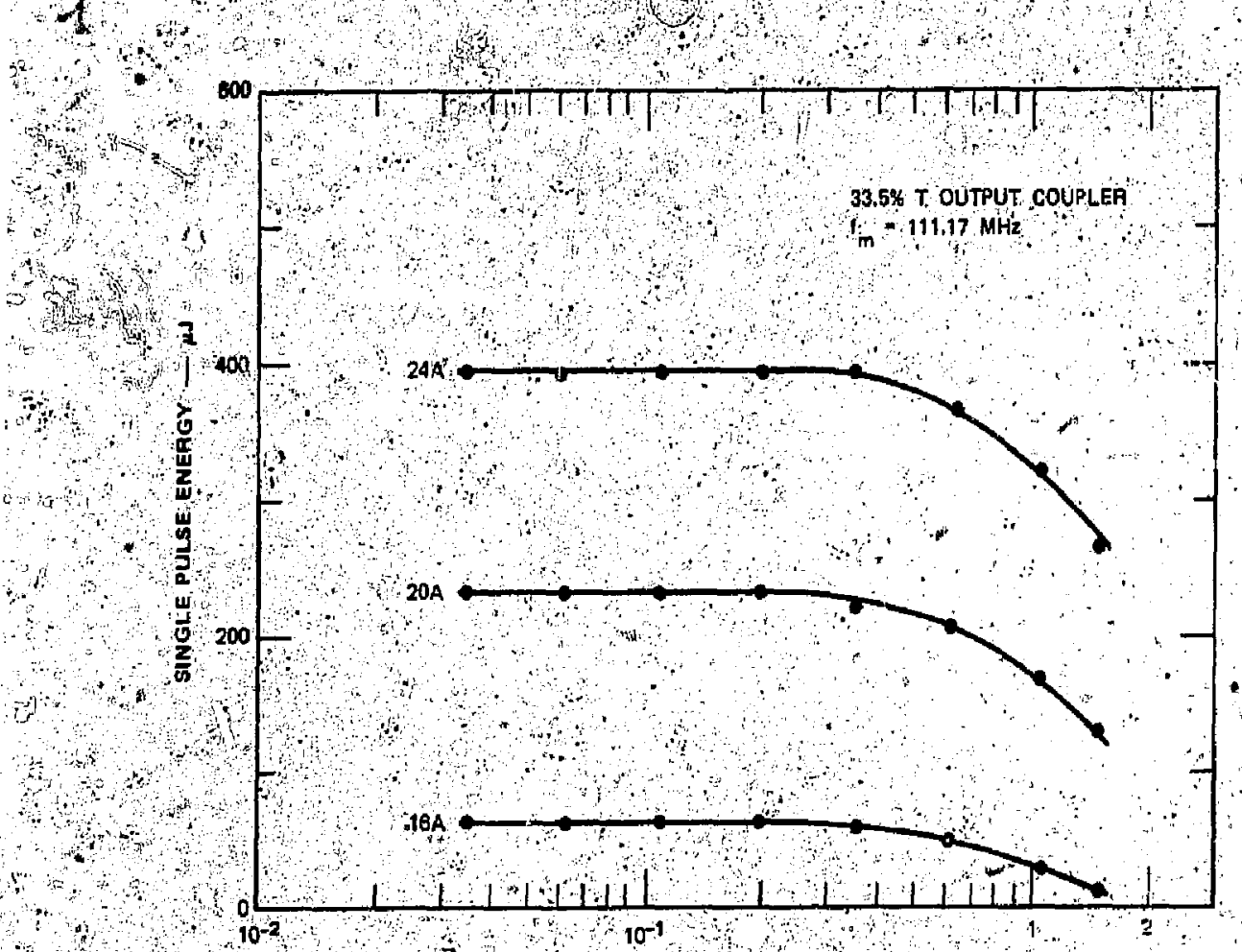

a

DEPT OF MOQULATION $-\theta$ or rods

$5 A-1908-5$.

FIGURE 5

Energy in a single pulse at the peak of the pulse train for varfous lamp

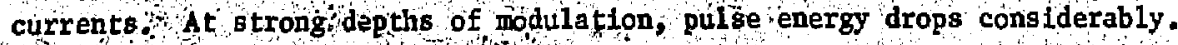
Pulse energles with the uncoted 1-cm etalon are approxinately the same as those without the etalor.
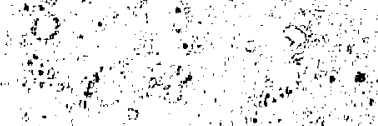

$$
\therefore=0
$$

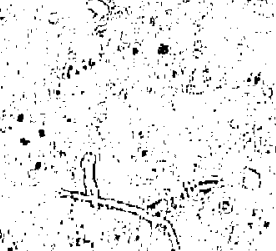




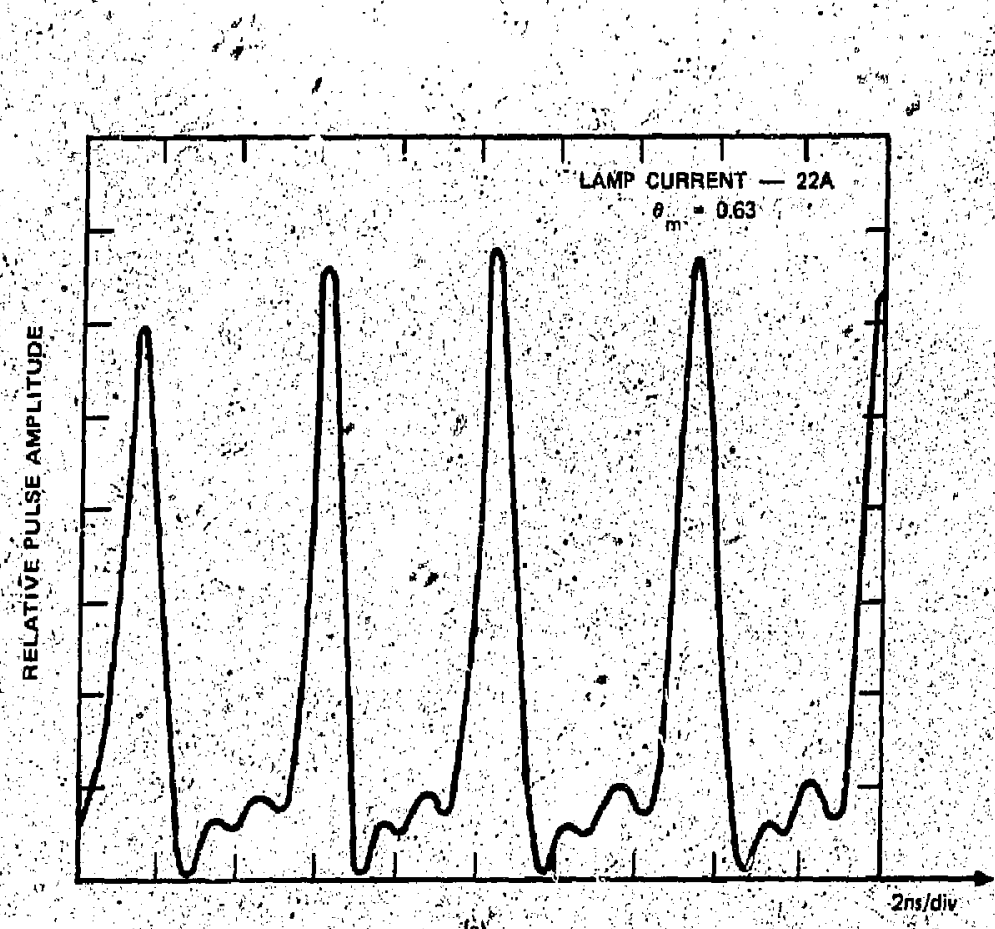

(a)

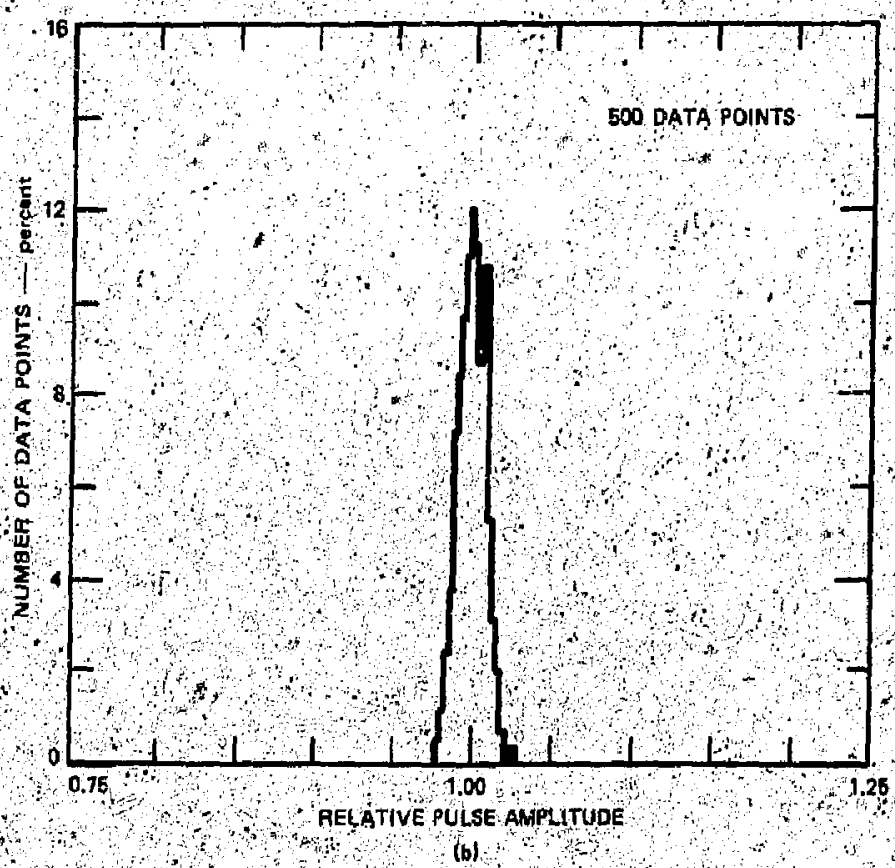

sA-400-6

Laser stability measurements. In (a), a pulse train is recorded with a transient digttizer. The computer then records the relative amplitude of apule at the peak of the pulse crain o the typical energy fluctuations

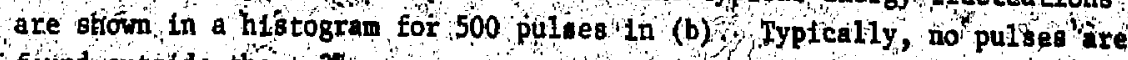
foud outside the $3 \%$ range. 
envelope is very stable. This effect oontributes considerably to the good otability of the laser reported above During the prelase period, the excess gain in the laser 18 very low, about $5 \%$ to $10 \%$ and hence transverse mode select lon ts very easy, and only for hlgh lamp currents is an lris needed to obtain ToM mode output.

The actual prelase signal $1 \mathrm{~s}$ also a fenarkable indlcation of how well the laber is worklng figure 7 stows some tjpical prelase signals for vathou conditions in the laser. These levels were recorded with a slow PIN 10 diode at the high reflector end of the laser as shown fn figure 1 . Wi th the modulator off, as shown in Figure $7(a)$, the relaxation oscll lation as the laser goes above thresholdare irregular; however, with good mod 1ocking, these oscillations become yexy regular when the cavity length $1 \mathrm{~s}$ slifhtly longer or shorter than that for good mode-locking, the laser goes Into driven relaxation oscillations as shown in F good mode-locking, the cavity length has to be adjus ted to within about 25 fom, and in practice this is done by observing the characteristic prelase levels as ohown in figure 7 All other measurements have shown that this thethod give the best performanee of the laser. It is rather remarkabie and extremely convenient that this lasez can be set up correctly with only a olow diode and an oscilloscope, other laser conditions, such as higher order transverse modes, which come above threshold later, are shown in Figure 7 (d).

The prelase signal, also Indlcated other problems in the laser. Smali instabilities in the o-switch driver, which could hardiy be observed on an oscilloscope, produced very strong ringling th the prelase level A signal generator for the modulator with short-term phase fluctuations also produced ringing. However, when a regular, stable prelase level is obtasned as show in Figure 7 (b), the laser to running very well.

Tests on the prototype laser were completed during september 1976, and it became clear that this type of laser was needed as soon as possible

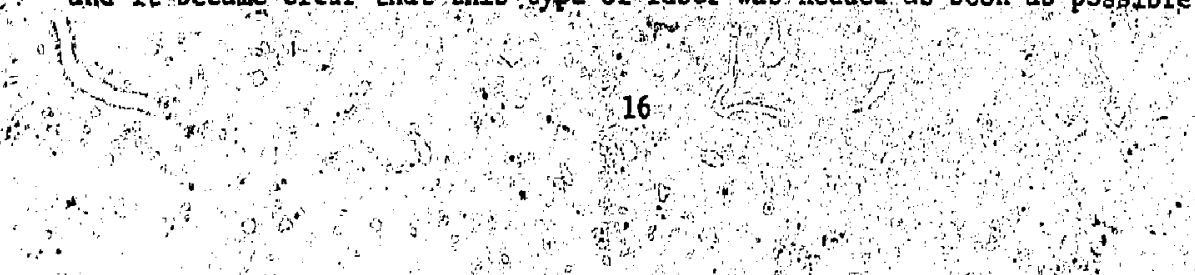




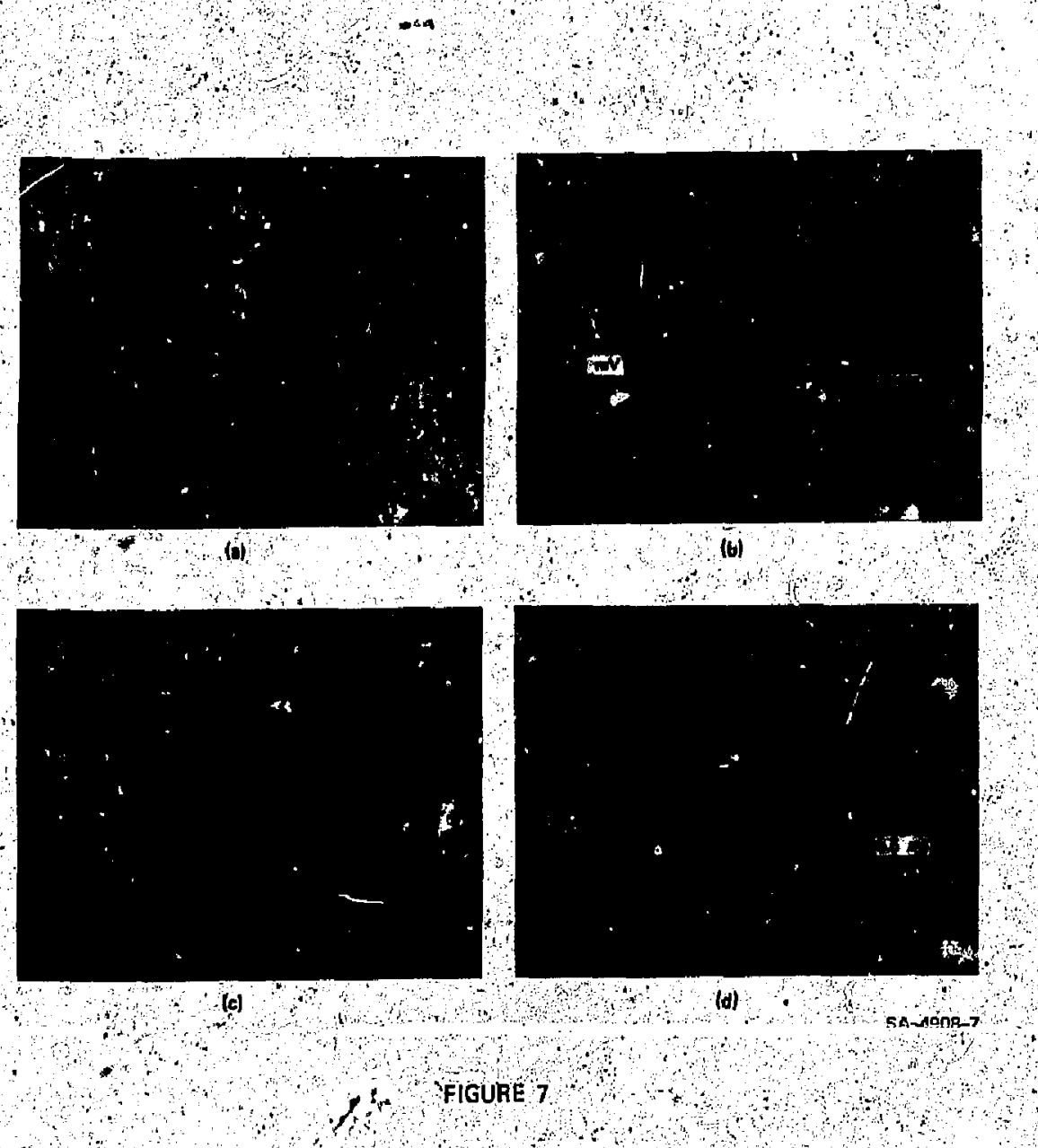

Laser prelase conations. The prelase signal 1 a very ascurate indication of the operation of the mode-locked and $\mathrm{Q}$-switched laser.t The pretase sfgnal wi th no modulation is shown in (a). With modulation, the relaxation oscillations becơte very stable (b). A slight cavity length change $(425$ i) caluses drifuén relaxatton osciliations, (c), and conditions such 1s higher order transverse modes, (d), can be identifled Note that only in (b) does the laser Q-switch at the end of tile prelase period. The energy in the $Q$-swithed puise relative to the above recording is about 4 V: 
for Argus, but the cavity length bad to be fopot $10^{-n}$ round trip time to obtaln good sirgle pulse selection. $A^{2}$ SR , we had an additional punp cavity, modulator, and $Q-8$ wtch, and we decfded to assemble such a laser for Argus at $S R I$ The laser was mourited in an Invar-stablilzed resonator used previously at IL for the PMo, In this lopg cavity, the spot size Was larget and the laser was nuch more senst tive to the thermal focussing In the rod, For this reason, the repetition rate of this laser had to be reduced to 5 pps The control electronics and lamp druver were further Inquoved and redestigned for easier operator control. The modulator and Q-owteh were both drtven at about 50 Mis, and the $Q$-owitch could be driven by the gane RF source as the modulator. The Q switch also opened at the same phase of the RF signal and, in this setup, the short pulses were synchronized with the opening of the $Q-s w i t c h$, and hence to the envelope of the $Q$-switched pulse train subsequent tests on the 1sser shored that the Iaser was now stable enough that a single pulie could be selected by counting a pedetermined number of cycles of the gF drive to the modulator from the time the $Q-$ switch is opened. This pulse selection nethod has not yet been inpleffented on Argus, but it will be used on the Shiva osclilator. This-degree of predictability with which a pulse is, available willenable good syachronization of this oscillator with other: ffast Instrumentation on Shiva,

Figure 8 shows the range of theasured pilse widths for the AIgus osctl1ator. The modulator has not yet been callbrated to give the depth of modulation and the pulse width in Figure 9 is given as a function of the RF level setting of the Hes signal generator. The shortest pulses avallable from this osclilator are about 110 psec because of the longer cavtfy used here. We liso noted that the range of good-mode-locking for this laser is considerably narrower than for the prototype laser. The reason for this is currently not kpown. Pulse widths pere measured without an ytalon, and with a 1-cm lincoated etalon. To cover the entire range of 


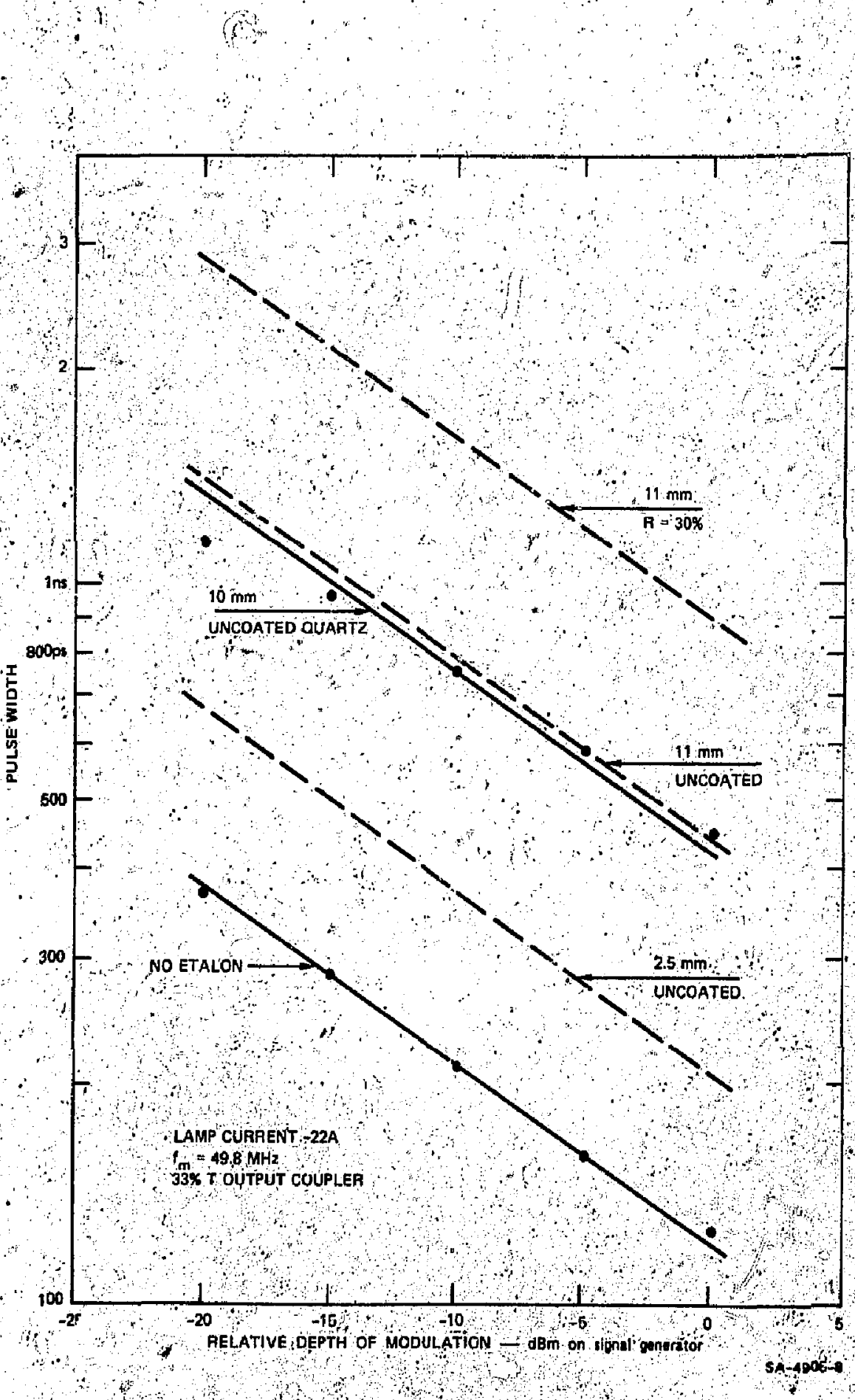

FIGURE 8

$\therefore$ Range of measured and predicted pulsesidth for the drgus oscillator. For this tong cavity $\left(\mathbf{f}_{\mathrm{m}}=50 \mathrm{MHz}\right)$, the shortest pulses available are about 110 ṕs. 

short fulses available from this laser, from about 120 ps to 3 ni, more etalons were required. The present oscillator on Argus now has thee etalons with the predicted pitsewtdth range show in Figure 8 .. Further neasurements ghoula conirur good operation of the laser over this entire range. Figure 9 shows the strigle pulse energles available from this laser. single short pulses of 600 of are routinely avallable from the laser, but the decrease of energy for strong moduiator drives is even more severe than for the shorter prototype laser. Further work should show the reason for this decrease in pulse erergy, This ofclilator is now operating success fully In the hlgh-EMI environment of Argus and is producing suceess ful target shots. 


\section{REFERENCES}

$1 \%$ ojer fuston Program Annual Report, pecenber 1975

$2.5, J$ Kuizenga and $A$ E.SLegman, WM and AM Mode-IockIng of the Hotogeneous Laser, Parts I and II, IEEE, JQE, QE-6, 694 (November $970 \%$

3. D, J. Kulzenga, D, WhLllon, T, Lund, and A, E Siegman, isinul taneous Q-gwtchlng and Mode-locklng in the CW Nd:YAG Laser, opties Com, 2,221 (Novenber 1973 ).

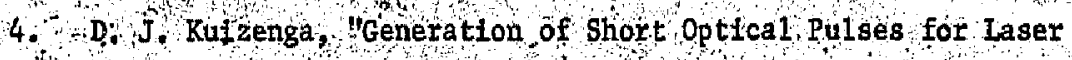
Fusfon, Final Report under p,0, No, 5241805 JUCLL), Report Ho. 2451 (Wcrowave Laboratory stanford Univers 1 ty), Report No, UCRL-13651 (UCLTL)

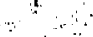

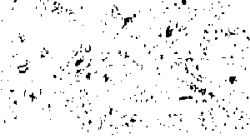

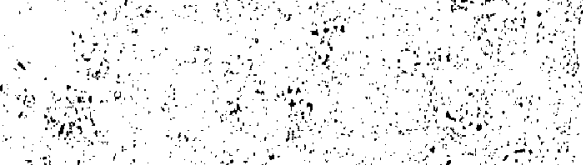

3

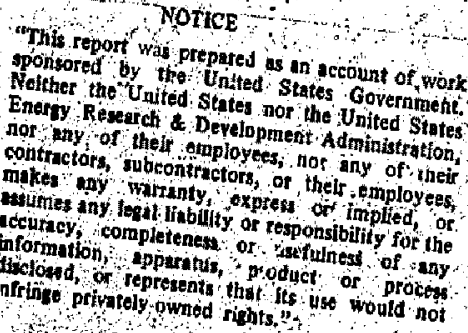

